\title{
Facing towards epidermal stem cells (Review)
}

\author{
ANELAURE SCHREDER, GERALD E. PIERARD, PHILIPPE PAQUET, MARIE-ANNICK REGINSTER, \\ CLAUDINE PIERARD-FRANCHIMONT and PASCALE QUATRESOOZ
}

Department of Dermatopathology, University Hospital Sart Tilman, B-4000 Liège, Belgium

Received February 19, 2010; Accepted April 16, 2010

DOI: 10.3892/ijmm_00000449

\begin{abstract}
Skin contains somatic stem cells that generate keratinocyte, melanocyte and mesenchymal cell lineages. These somatic stem cells have traditionally been thought to be restricted in their differentiation and regeneration potential to the tissues in which they reside. This review focused on epidermal stem cells (ESCs). These cells are distinguished from transitory amplifier cells and post-mitotic cells. ESC are found in the interadnexal epidermis and in the bulge region of hair follicles. A series of ESCs markers are available, but increased sensitivity and specificity require further development.
\end{abstract}

\section{Contents}

1. Introduction

2. Epidermal stem cells

3. Identification and location of epidermal stem cells

4. Proliferative epidermal units

5. Stem cells in the hair follicles

6. Plasticity of epidermal stem cells

7. Epidermal stem cell markers

8. Conclusion

\section{Introduction}

The superficial layer of human skin consists of the interfollicular epidermis pierced by the openings of appendages including the pilosebaceous follicles and sweat ducts. Keratinocytes are the most abundant epidermal cells. The interfollicular epidermis consists of a few layers of keratinocytes forming a dynamic tissue that is constantly subject to self-renewal. The basal cell layer abutted to the dermoepidermal basement membrane, contains keratinocytes capable of dividing or leaving the basal layer to differentiate while they move outwards in the direction of the skin surface. The final product of this maturation process is the anucleated corneocytes forming the stratum corneum.

Correspondence to: Professor Gérald E. Piérard, Department of Dermatopathology, CHU Sart Tilman, B-4000 Liège, Belgium E-mail: Gerald.pierard@ulg.ac.be

Key words: epidermal stem cell, epidermis, keratinocyte, melanocyte

\section{Epidermal stem cells}

Stem cells (SCs) are capable of reproducing themselves in an undifferentiated state for prolonged and indeterminate periods of time. They may differentiate themselves, and transform into more than one single type of cell with defined functions (1). Therefore, the main SC characteristics are (a) pluri- or multipotency (the ability to differentiate into different cell types), (b) plasticity (the ability to generate tissue types other than the tissue of origin), (c) quiescence (low rate of cell renewal), and (d) high proliferative potential (boosted division rate when exposed to appropriate stimuli) $(2,3)$. Such SCs are found in embryos (embryonic SC) and in postnatal life (somatic SC) in various tissues such as skin, bone marrow, and liver (4-6).

Embryonic SCs are pluripotent while somatic SCs are multipotent because they have a restricted capability to generate different cell types $(4,7)$. Therefore, somatic SCs correspond to undifferentiated cells present in tissues and organs. They are capable of generating some cell types present in the organ. Throughout life new keratinocytes are required to replace the corneocytes that are shed from the skin surface $(8,9)$. Similarly, new hairs need to be produced in order to replace those lost at teloptosis (exogen phase) $(10,11)$. The specialisation of somatic SCs depends on the environment and growth factors to which they are exposed. Histospecific SCs are found in the epidermis and hair follicles. According to the microenvironment, the epidermal SCs differentiate into different cell types.

\section{Identification and location of epidermal stem cells}

Epidermal stem cells (ESCs), transitory amplifier cells (TACs) and post-mitotic cells (PMCs) are present in the basal layer of the epidermis $(9,12-14)$. ESCs represent epidermal progenitor cells. They exhibit high potential for proliferation and they show almost unlimited capacity for self-renewal. However, in regular conditions, they are characterized by a low rate of cell proliferation. Hence, they remain labeled for long periods of time after being exposed to tritiated thymidine $\left({ }^{3} \mathrm{H}-\mathrm{TdR}\right)$ or bromodeoxyuridine (BrdU). These markers are retained for about one year in ESCs, demonstrating their quiescence. Although in vivo these cells do not commonly divide, they do so quickly in response to specific threats and in cell culture $(15,16)$.

ESC daughter cells correspond to TACs undergoing terminal maturation/differentiation after dividing 3-5 times before leaving the basal layer. Their potential for differentiation is considered to be more restricted than that of ESCs. The next 
step in TAC differentiation produces PMCs that may remain attached to the basement membrane, but no longer divide. They are indeed engaged in the G0 phase of the cell cycle. Most of them start both their differentiation and migration processes, moving outwards from the basement membrane.

The average ESC produces one ESC and one non-ESC, although two daughter ESCs or non-ESCs may be produced, depending on the physiological needs of the tissue. In addition they are vital for maintaining the pools of ESCs, TACs and PMCs. It is assumed that depending on the plane of the mitosis orientation one or both of the daughter cells may stay anchored to the basement membrane and therefore they will not differentiate $(15,17)$. Using ${ }^{3} \mathrm{H}-\mathrm{TdR}$, BrdU, or some other markers, it is possible to locate these ESCs in the epidermis and hair follicles.

There is evidence of ESCs in the bulge region of the hair follicles (18-20), as well as in the interfollicular epidermis $(1,21)$. When the epidermis suffers severe damage, it may completely regenerate from the ESCs of the bulge (15). The ESCs present in the bulge and interfollicular epidermis are potentially interconvertible, but under regular conditions they only differentiate a more restricted progeny.

The notion that one-way progression from ESCs to TACs is not correct; in certain circumstances, there is evidence showing TACs being transformed into SCs. Therefore, the real role of SCs or TACs in the differentiation remains to be established. It is uncertain when this role is acquired in gene functions, and what factors or markers are carried by differentiating or de-differentiating cells.

\section{Proliferative epidermal units}

The basal layer of the interfollicular epidermis contains a few ESCs $(\sim 0.01 \%)$ (22), TACs $(\sim 40 \%)$ and PMCs $(\sim 50 \%)$, as well as Langerhans cells $(\sim 10 \%)$, melanocytes $(\sim 3 \%)$ and Merkel cells (23).

In humans it was observed that in the epidermis of the scalp, foreskin and breast, ESCs are located at the tip of the dermal papillae, while on the palms and soles they are located at the tip of the rete ridges (24-27). Since ESCs are located in the central region of each proliferative epidermal unit in the basal layer or in the bulge region of the hair follicles, they are in a special site protected from any possible environmental damage $(28,29)$.

The TAC population is the target for neoplasic transformations and skin field cancerization (30-32). Cells with the highest risk of acquiring mutations are in a stage of cell division. Therefore the risk is higher in rapidly-renewing tissues like the epidermis. The probability of accumulating multiple mutations throughout life is minimised by the greater proliferative activity to cells that differentiate rapidly, while SCs, which are longterm residents, remain relatively quiescent $(33,34)$.

\section{Stem cells in the hair follicles}

${ }^{3} \mathrm{H}-\mathrm{TdR}$ label-retaining cells (LRCs) are present in the upper third of the external root sheath identified as the bulge region under the site of attachment of the hair arrector muscle (35). The bulge area is also a niche for some melanocyte SCs, immature Langerhans and other immunocytes as well $(5,34)$.
At the beginning of each hair growth cycle, ESCs in the bulge migrate downwards through the external root sheath and upon reaching the hair matrix are stimulated and differentiate, producing a new hair structure. Cell migration in the external root sheath reaches $\sim 70-100 \mu \mathrm{m}$ per day. Therefore, it takes ESCs between three and four weeks to move a distance of $2 \mathrm{~mm}$, the distance that separates ESCs in the bulge from the matrix of a mature hair follicle, and the time coincides with the duration of the earliest anagen phases of the hair (35).

\section{Plasticity of epidermal stem cells}

Somatic SCs have the potential capacity called plasticity to differentiate outside the organ in which they reside. Some examples are cells obtained with the hepatocyte, neuron and muscle cell phenotypes obtained from adult haematopoietic SCs.

Cells expressing markers from other lineages are observed when skin cells are stimulated by different growth factors. The plasticity characteristic has been established when differentiation leads to non-epithelial cells such as those exhibiting phenotypes of neurons and Schwann cells $(4,36)$.

\section{Epidermal stem cell markers}

Similar to other tissues, there is a need for identifying characteristic molecular markers of ESCs, preferably cell surface markers that allow ESCs, TACs, PMCs and other cell types present in the epidermis to be identified and distinguished $(37,38)$

Regulation of the epidermal kinetics is complex and multifactorial. It involves the tissue cells themselves, the molecules they produce, and cells and molecules produced by the surrounding tissues (39-41). Factors affecting the epidermal proliferation and repair include the secretion of growth factors and the presence of their receptors, transcription regulators (such as KGF, IL-1, GM-CSF, c-jun, jun-b), extracellular matrix (ECM) molecules and their receptors (such as laminins and integrins), molecular regulators (such as Shh, Wnt/ß catenins, NF-кB, c-Myc, p63 and Rac-1) (16).

p63 is a transcription factor belonging to a family that includes an additional two structurally-related proteins, p53 and p73 (42). Although p53 fulfils an important role in tumour suppression, p63 and p73 participate in morphogenetic processes (43). Their expression is evidenced in ESCs. Disruptions in the gene lead to faults in epidermal development. p63 is expressed in the nucleus of a cell in proliferation or with the capacity to divide, in the human epidermis and hair follicles.

The co-expression of specific keratin pairs is specified by the type of epithelium and, in a given epithelium, the cell layer is specific, reflecting the state of cellular differentiation (41). Changes in keratin expression allow basal keratinocytes to be distinguished from those belonging to upper layers showing a higher degree of differentiation. The initial keratins expressed are $\mathrm{K} 14$ and $\mathrm{K} 5$. The differentiation process is correlated with K10/K1 expression. Epibasal keratinocytes keep K5/K14 in their cytoplasm and begin to synthesize $\mathrm{K} 1 / \mathrm{K} 10$, forming the cytoskeleton. These keratins are typical for epidermal differentiation patterns, and are called differentiation-specific 
keratins. K15 is persent in human hair bulge cells, and its expression decreases with age $(34,44,45)$. Desmosomal proteins including desmoglein may serve as negative markers of ESCs (46).

Integrins are glycoproteins corresponding to $\alpha$ and $\beta$ heterodimers located at the cell surface. Human keratinocytes express a variety of receptors from the integrin family, including $\alpha 2 \beta 1$ integrin (collagen receptor) and $\alpha 3 \beta 1$ and $\alpha 5 \beta 1$ integrin (receptors of laminin and fibronectin, respectively). Thus, integrins mediate the anchoring of basal keratinocytes to the basement membrane. In addition, they participate in the intercellular communication. One of the main markers is $\beta_{1}$ integrin expressed by all cells in the basal layer of the epidermis. Notably, the ESCs express levels that are two or three times higher than TACs, while PMCs express very low levels. The density of $\beta 1$ integrin on the cell surface plays an important role in the control of different aspects of epidermal differentiation and morphogenesis. Another type is $\alpha 6$ integrin, a component of hemidesmosomes. When keratinocytes start the differentiation process, transport of integrins to the surface of the cell ceases and these receptors are lost from the cell surface.

CD71 is the transferrin receptor $(15,34,35)$ representing another surface marker that allows the distinction between the SC and progeny in its expression. TACs express high levels of CD71 and $\alpha 6$ integrins (40).

CD34 is a haematopoietic marker in humans. It is observed in mouse bulge cells, but not in humans $(34,45,47)$. It is also present in some dermal dendrocytes.

Nestin expression has been reported in ESCs located in the bulge of the hair follicle. Variations in nestin expression have been reported depending on the stage of the hair growth cycle. During the telegen and catagen stages, nestin is observed in the bulge region, while during the anagen phases it is observed in the outer part of the outer root sheath and in the hair bulge $(40,45)$. In addition, nestin-expressing cells expressed K5/K8 and K15 hair follicle SC markers (48).

High levels of CD59 are expressed by bulge cells as well as in the outer root sheath below the bulge. By contrast, the CD24 is not expressed in bulge cells and thus represents a negative marker. This glycoprotein is involved in cell adhesion and signal in lymphocytes and neural cells.

CD200 is expressed by cells of the outer root sheath in the region between the attachment of the arector muscle and the bulge (49). Interaction of CD200 with its receptor is involved in the maintenance of immunotolerance, preventing the immune system from attacking the hair follicle.

The results suggest hair follicle cells present the phenotype with high levels of CD200 and K15 and low levels of CD24, CD34, CD71 expression (20). ESCs express high levels of $ß 1$ and $\alpha 6$ integrins, K14 with low levels of expression of CD71, $\mathrm{K} 10$ and involucrin. TACs express high levels of $B 1$ and intermediate levels of $\alpha 6$ integrin, K14 and CD71, and they do not express K10 and involucrin. PMCs express high levels of $\mathrm{K} 14$, K10, involucrin with very slight levels of $\beta 1 \alpha 6$ integrin.

\section{Conclusions}

Skin represents a model for the study of somatic SC, as it is easily accessible. Understanding ESCs helps with the therapeutic applications of keratinocytes. The combination of transduction protocols with the use of retroviral vectors could allow ESCs to be used for gene therapy in the future. Using SCs and their progeny is useful for different purposes. They are used for study models of epidermal organisation, and because they are influenced by keratinocytes and ESCs due to the microenvironment surrounding them.

The use of proteomic determination and microarrays could provide additional SC and TAC markers, allowing pure populations to be obtained and other studies to be carried out to obtain more comprehensive information about them.

The colonisation of solid organs by organ-specific SCs obtained from circulating blood suggests that regeneration and repair is easily accessible when these SCs are placed in circulating blood near to or in the affected site. Their capacity to proliferate and mature is modulated once they are in the appropriate location. The use of somatic SCs, which offer similar multipotency as embryonic SCs, has the advantage of being a procedure that does not involve ethical and technical concerns.

The potential clinical application requires SCs to be easily accessible, in sufficiently high concentrations and capable of being stimulated using different factors as needed. These conditions are met by ESCs, given that the skin is the largest organ in the human body, and represents an abundant SC reserve in the organism. There are $\sim 5$ million hair follicles in the organism, each one containing its own bulge region where a large number of ESCs are present.

ESCs from adult tissues could be used to treat skin disorders such as cancers, deep burns, atrophies, and alopecia. For treating alopecia, ESCs from hair follicles could potentially generate new follicles in the scalp. They could be used more widely for treating genetic and acquired disorders affecting other organs and tissues. For example, SCs could be isolated, modified, expanded before being reimplanted in the same or another patient or location. The key problem is to control their proliferation and differentiation. Before applying SC therapies the proliferative and differentiation of a specific cell type must be strictly controlled, as must the risks involved from inappropriate cell functions.

\section{Acknowledgements}

This work was supported by a grant from the 'Fonds d'Investissement de la Recherche Scientifique' of the University Hospital of Liège. No other sources of funding were used to assist in the preparation of this manuscript. The authors appreciate the excellent secretarial assistance of Mrs. Ida Leclercq.

\section{References}

1. Abbas $\mathrm{O}$ and Mahalingam M: Epidermal stem cells: practical perspectives and potential uses. Br J Dermatol 161: 228-236, 2009.

2. Körbling $\mathrm{M}$ and Estrov $\mathrm{Z}$ : Adult stem cells for tissue repair, a new therapeutic concept? N Engl J Med 349: 570-582, 2003.

3. Verstappen J, Katsaros C, Torensma R and Von den Hoff JW: A functional model for adult stem cells in epithelial tissues. Wound Repair Regen 17: 296-305, 2009.

4. Adameyko I, Lallemend F, Aquino JB, Pereira JA, Topilko P, Müller T, Fritz N, Beljajeva A, Mochii M, Liste I, Usoskin D, Suter U, Birchmeier C and Ernfors P: Schwann cell precursors from nerve innervation are a cellular origin of melanocytes in skin. Cell 16: 366-379, 2009. 
5. Cramer SF: Stem cells for epidermal melanocytes - a challenge for students of dermatopathology. Am J Dermatopathol 31: 331-341, 2009.

6. Oishi K, Noguchi H, Yukawa H and Hayashi S: Differential ability of somatic stem cells. Cell Transplant 18: 581-589, 2009.

7. Blanpain C, Lowry W, Geoghegan A, Polak L and Fuchs E: Self-renewal multipotency, and the existence of two cell populations within an epithelial stem cell niche. Cell 118 635-648, 2004.

8. Koster MI: Making an epidermis. Ann NY Acad Sci 1170: 7-10, 2009.

9. Berta MA, Baker CM, Cottle DL and Watt FM: Dose and context dependent effects of Myc on epidermal stem cell proliferation and differentiation. EMBO Mol Med 2: 16-25, 2010 .

10. Piérard-Franchimont $\mathrm{C}$ and Piérard GE: Teloptosis, a turning point in hair shedding biorhythms. Dermatology 230: 115-117, 2001

11. Piérard-Franchimont C, Petit L, Loussouan G, Saint Léger D and Piérard GE: The hair eclipse phenomenon: sharpening the focus on the hair cycle chronobiology. Int J Cosmet Sci 25: 295-299, 2003 .

12. Winter MC and Bickenbach JR: Aging epidermis is maintained by changes in transit-amplifying cell kinetics, not stem cell kinetics. J Invest Dermatol 56: 181-187, 2009.

13. Charruyer A, Barland CO, Yue L, Wessendorf HB, Lu Y, Lawrence HJ, Mancianti ML and Ghadially R: Transitamplifying cell frequency and cell cycle kinetics are altered in aged epidermis. J Invest Dermatol 129: 2574-2589, 2009

14. Guo A and Jahoda CA: An improved method of human keratinocyte culture from skin explants: cell expansion is linked to markers of activated progenitor cells. Exp Dermato 118: 720-726, 2009.

15. Watt F, Lo Celso C and Sila-Vargas V: Epidermal stem cells: an update. Curr Opin Genet Develop 16: 518-524, 2006.

16. Kaur P: Interfollicular epidermal stem cells: identification, challenges, potential. J Invest Dermatol 126: 1450-1458, 2006.

17. Alonso L and Fuchs E: Stem cells in the skin: waste not, WNT not. Genes Develop 17: 1189-1200, 2003.

18. Myung P, Andl T and Ito M: Defining the hair follicle stem cell (Part I). J Cutan Pathol 36: 1031-1034, 2009.

19. Myung P, Andl T and Ito M: Defining the hair follicle stem cell (Part II). J Cutan Pathol 36: 1134-1137, 2009.

20. Zhang YV, Cheong J, Ciapurin N, McDermitt DJ and Tumbar T: Distinct self-renewal and differentiation phases in the niche of infrequently dividing hair follicle stem cells. Cell Stem Cell 5: 267-278, 2009

21. Ambler CA and Määttä A: Epidermal stem cells: location, potential and contribution to cancer. J Pathl 217: 206-216, 2009.

22. Schneider T, Barland C, Alex A, Mancianti M, Lu Y, Cleaver J, Lawrence $\mathrm{H}$ and Ghadially R: Measuring stem cell frequency in epidermis: a quantitative in vivo functional assay for long term repopulating cells. Proc Natl Acad Sci USA 100: 11412-11417, 2003.

23. Morris R: Keratinocyte stem cells: targets for cutaneous carcinogens. J Clin Invest 106: 3-8, 2000.

24. Liang L and Bickerbach J: Somatic epidermal stem cells can produce multiple cell lineages during development. Stem Cells 20: 21-31, 2002

25. Tumbar T, Guash G, Greco V, Blanplain C, Lowry W, Rendl M and Fuchs E: Defining the epithelial stem cell niche in skin. Science 303: 359-363, 2004.

26. Barthel R and Aberdam D: Epidermal stem cells. J Eur Acad Dermatol Venereol 19: 405-413, 2005.

27. Ghazizadeh S and Taichman L: Organization of stem cells and their progeny in human epidermis. J Invest Dermatol 124 : 367-372, 2005

28. Slack J: Stem cells in epithelial tissues. Science 287: 1431-1433, 2000 .
29. Savill N and Sherratt J: Control of epidermal stem cell clusters by Notch-mediated lateral induction. Develop Biol 258: 141-153, 2003.

30. Quatresooz P, Piérard-Franchimont C, Paquet P, Hubert P Delvenne $\mathrm{P}$ and Piérard GE: Crossroads between actinic keratosis and squamous cell carcinoma, and novel pharmacological issues. Eur J Dermatol 18: 6-10, 2008.

31. Lorz C, Segrelles C and Paramio JM: On the origin of epidermal cancers. Curr Mol Med 9: 353-364, 2009.

32. Quatresooz P, Xhauflaire-Uhoda E, Piérard-Franchimont C and Piérard GE: Epidermal field carcinogenesis in bald-headed: An attempt at finetuning early non-invasive detection. Oncol Rep 21: 1313-1316, 2009

33. Janes S, Lowell S and Hutter C: Epidermal stem cells. J Pathol 197: 479-491, 2002.

34. Cotsarelis G: Epithelial stem cells: a folliculocentric view. J Invest Dermatol 126: 1459-1468, 2006.

35. Oshima H, Rochat A, Kedzia C, Kobayashi K and Barrandon Y: Morphogenesis and renewal of hair follicles from adult multipotent stem cells. Cell 104: 233-245, 2001

36. Sieber-Blum M: Pluripotent neural crest stem cells in the adult hair follicle. Develop Dynamics 231: 258-269, 2004.

37. Green H, Easley $\mathrm{K}$ and Iuchi S: Marker succession during the development of keratinocytes from cultured human embryonic stem cells. Proc Natl Acad Sci USA 100: 15625-15630, 2003.

38. Inoue K, Aoi N, Sato T, Yamauchi Y, Suga H, Eto H, Kato H, Araki J and Yoshimura K: Differential expression of stem-cellassociated markers in human hair follicle epithelial cells. Lab Inest 89: 844-856, 2009

39. Tani H, Morris R and Kaur P: Enrichment for murine keratinocyte stem cells based on cell surface phenotype. Proc Natl Acad Sci USA 97: 10960-10965, 2000.

40. Li A, Pouliot N, Redvers R and Kaur P: Extensive tissueregenerative capacity of neonatal human keratinocyte stem cells and their progeny. J Clin Invest 113: 390-400, 2004.

41. Rice C and Scolding N: Adult stem cells - reprogramming neurological repair? Lancet 364: 193-199, 2004.

42. Klein AM, Brash DE, Jones PH and Simons BD: Stochastic fate of p53-mutant epidermal progenitor cells is tilted toward proliferation by UVB during preneoplasia. Proc Natl Acad Sci USA 107: 270-275, 2010.

43. Pellegrini G, Dellambra E, Golisano O, Martinelli E, Fantozzi I, Bondanza S, Ponzin D, McKeon F and De Luca M: P63 identifies keratinocyte stem cells. Proc Natl Acad Sci USA 98: 3156-3161, 2001.

44. Al-Refu K, Edward S, Ingham E and Goodfield M: Expression of hair follicle stem cells detected by cytokeratin 15 stain: implications for pathogenesis of the scarring process in cutaneous lupus erythematosus. Br J Dermatol 160: 1188-1196, 2009.

45. Hoang MP, Keady M and Mahalingam M: Stem cell markers (cytokeratin 15, CD34 and nestin) in primary scarring and nonscarring alopecia. Br J Dermatol 160: 609-615, 2009.

46. Wan H, Stone M, Simpson C, Reynols L, Marshall J, Hart I, Dilke $\mathrm{K}$ and Eady R: Desmosomal proteins, including desmoglein 3 , serve as novel negative markers for epidermal stem cell-containing population of keratinocytes. J Cell Sci 116: 4239-4248, 2003

47. Miller SJ: CD34, stem cells and the skin. Arch Dermatol 130: 624-626, 1994.

48. Li L, Mignone J, Yang M, Matic M, Penman S, Enikolopov G and Hoffman R: Nestin expression in hair follicle sheath progenitor cells. Proc Natl Acad Sci USA 100: 9958-9961, 2003.

49. Ohyama M, Terunuma A, Tock CL, Rdonovich MF, Pise-Masison CA, Hopping SB, Brady JN, Udey MC and Vogel JC: Characterization and isolation of stem cell-enriched human hair follicle bulge cells. J Clin Invest 116: 249-260, 2006. 